\title{
Mass media as a source of trauma after Armavia jet crash in May 2006 in Sochi Maruke Yeghiyan* and Khachatur Gasparyan
}

Address: Department of Psychiatry, Yerevan State Medical University, Armenia

* Corresponding author

from International Society on Brain and Behaviour: 3rd International Congress on Brain and Behaviour

Thessaloniki, Greece. 28 November - 2 December 2007

Published: 17 April 2008

Annals of General Psychiatry 2008, 7(Suppl I):S2 doi:I0.I 186/I744-859X-7-SI-S2

This abstract is available from: http://www.annals-general-psychiatry.com/content/7/SI/S2

(c) 2008 Yeghiyan and Gasparyan; licensee BioMed Central Ltd.

\section{Background}

The aim of this presentation is to show the influence of trauma on the psychological well being of the general population after mass media reports.

\section{Materials and methods}

The following steps were important: creation of "Hot line" psychological help services for the families of the victims and also for general population; public education; professional education; publication of materials such as a children and grief.

\section{Results}

Different stages of post traumatic stress reactions were observed: up to mid June, 40th Day memorial mass, acceptance by the family members loss as a reality; the mourning process continues recurring, sometimes reexperiencing the tragedy of the event, anger as psychological reaction after traumatic loss.

\section{Conclusions}

Those families who were not able to find the remains of their loved once having longer denial and mourning processes. The main sources of the news and their 24 hours a day reports about increased details of the private lives of the families who lost a member, detailed and repetitive visual coverage of jet crash. Data and statistical analysis of the calls showing that less then $10 \%$ of the calls are from the families of the victims and the rest was from general population. Mass media and in most of the cases television can be a powerful influence in developing post traumatic reactions, not necessarily disorders.
The electronic version of this abstract is the complete one and can be found online at: http://www.annals-generalpsychiatry.com/content/7/S1/S2 